\title{
Value of combined phenotypic markers in identifying inheritance of familial adenomatous polyposis
}

\author{
F M Giardiello, G J A Offerhaus, E I Traboulsi, J C Graybeal, I H Maumenee, A J Krush, \\ L S Levin, S V Booker, S R Hamilton
}

\begin{abstract}
Familial adenomatous polyposis is an autosomal dominant disease characterised by the development of hundreds of colorectal adenomas in young adults. Occult radioopaque jaw lesions and pigmented ocular fundus lesions (formerly called congenital hypertrophy of the retinal pigment epithelium) are extraintestinal phenotypic markers for this disorder. We evaluated the usefulness of the combination of these markers for identifying patients who have inherited familial adenomatous polyposis. Forty three affected patients and 12 unaffected first degree relatives from 24 families with familial adenomatous polyposis, including four families without extraintestinal manifestations, were examined for both phenotypic markers. Thirty three of the 43 patients $(77 \%)$ with familial adenomatous polyposis were positive for both markers, including patients from two families without extraintestinal manifestations. By contrast, only one of $12(8 \%)$ unaffected first degree relatives over 35 years of age had both markers. The sensitivity of the combination of these markers in identifying patients who inherited familial adenomatous polyposis was $77 \%$, the specifcity $92 \%$, the predictive value of a positive test $97 \%$, the predictive value of a negative test $52 \%$, and the efficacy $80 \%$. The combined markers had improved efficacy over either marker alone $\mathbf{7 0} \%$ for occult radio-opaque jaw lesions and $67 \%$ for pigmented ocular fundus lesions). We conclude that the presence of both occult radio-opaque jaw lesions and pigmented ocular fundus lesions in a person at risk indicates a high probability of inheritance and expression of familial adenomatous polyposis.
\end{abstract}

Familial adenomatous polyposis is an autosomal dominant disorder characterised by the development during adolescence and young adulthood of hundreds to thousands of colorectal adenomas. ${ }^{\prime}$ If prophylactic colectomy is not performed virtually all affected subjects will develop colorectal cancer by the fifth decade of life. Familial adenomatous polyposis can be associated with extraintestinal lesions (Gardner syndrome) such as benign soft tissue and bony tumours, desmoid tumours, and extraintestinal cancers. Colorectal polyposis can also occur without these extraintestinal manifestations ('familial polyposis coli'). ${ }^{1-3}$

Two extraintestinal phenotypic markers have recently been described. Occult radio-opaque jaw lesions are small, usually multiple, well circumscribed radiodensities detected by panoramic $x$ rays in the premolar and molar regions of the mandible and maxilla. These lesions were first associated with familial adenomatous polyposis by Utsunomiya and Nakamura in $1975 .{ }^{+}$In 1987 Offerhaus et $a l^{5}$ reported that occult radio-opaque jaw lesions predicted the development of polyposis in seven children at risk. A second phenotypic marker is pigmented ocular fundus lesions, formerly called congenital hypertrophy of the retinal pigment epithelium. These discrete, round to oval, darkly pigmented areas range from $0 \cdot 1$ to $1 \cdot 0$ optic-disc diameters in size and are detected by indirect ophthalmoscopy. ${ }^{6}$ These lesions consist of multiple hyperplastic layers of retinal pigment epithelium with hypertrophied cells filled with large spherical melanosomes often in clusters. ${ }^{7}$ The presence of these in patients with familial adenomatous polyposis was first described by Blair and Trempe in $1980 .{ }^{8}$ Subsequently, we found that the presence of four or more such lesions was a specific phenotypic marker for and predictor of familial adenomatous polyposis. ${ }^{69}$

Occult radio-opaque jaw lesions and isolated patches of congenital hypertrophy of the retinal pigment epithelium, which is ophthalmoscopically indistinguishable from pigmented ocular fundus lesions of familial adenomatous polyposis, each occur in a small percentage of the general population. ${ }^{1-4}$ Dental lesions are found in $0-10 \%$ of the general population, usually as a single focus and more often in elderly edentulous people. ${ }^{510-12}$ These lesions are frequently inflammatory lesions resulting from tooth decay. The frequency of isolated patches of congenital hypertrophy of the retinal pigment epithelium was assumed by Lewis and coworkers to be 1 in 1000 subjects because data for the general population were not available. ${ }^{13}$ Traboulsi and coworkers found one ocular fundus lesion in one eye of one third of their control group and one in each eye of two of 42 spouse controls. ${ }^{6}$ The simultaneous occurrence of both occult radioopaque jaw lesions and one patch of pigmented ocular fundus lesions in a normal subject should be rare, the probability being the product of the two frequencies (conservatively estimated at less than 1 in 200 normal subjects. As a consequence the combination of the two types of lesions may be more useful in identifying subjects who have inherited adenomatous polyposis than either marker alone.

The purpose of this study was to determine the diagnostic usefulness of a combination of occult radio-opaque jaw lesions and at least one pig- 
TABLE I Study subjects in categories according to age and sex

\begin{tabular}{lcll}
\hline Subjects & $M / F$ & $\begin{array}{l}\text { Kindred type: } \\
\text { EIM/noEIM* }\end{array}$ & $\begin{array}{l}\text { Mean age } \\
\text { (range) (years) }\end{array}$ \\
\hline $\begin{array}{l}\text { All subjects }(\mathrm{n}=55) \\
\text { Patients with familial } \\
\begin{array}{l}\text { adenomatous polyposis } \\
(\mathrm{n}=43)\end{array}\end{array}$ & $27 / 28$ & $49 / 6$ & $37 \cdot 9(12-72)$ \\
$\begin{array}{l}\text { First degree relatives }>35 \\
\text { years of age }(\mathrm{n}=12)\end{array}$ & $20 / 23$ & $40 / 3$ & $35 \cdot 1(12-72)$ \\
\hline
\end{tabular}

${ }^{\star} \mathrm{EIM}=$ extraintestinal manifestations. Twenty kindreds had members with EIM and four kindreds lacked EIM.

mented ocular fundus lesion in subjects at risk for familial adenomatous polyposis.

\section{Methods}

STUDY POPULATION

All pedigrees were selected from the Johns Hopkins Polyposis Registry used in our previous studies. ${ }^{56}$ The study protocol was approved by the joint committee on clinical investigation of the School of Medicine. Informed consent was obtained for panoramic dental radiographs and for indirect ophthalmoscopic examination after pupillary dilation from all subjects or their parents in the case of minor children.

The examinations were performed on 55 subjects from 24 families with familial adenomatous polyposis. Twenty families were classified as familial adenomatous polyposis with extraintestinal manifestations and four families as familial adenomatous polyposis without evident extraintestinal lesions. A family was labelled as having extraintestinal manifestations when two or more of the affected members had any of the following lesions: osteoma, epidermal inclusion cyst, subcutaneous fibroma, desmoid tumor, or extraintestinal carcinoma as described by Bussey.' Of the 55 subjects examined, 43 were patients with familial adenomatous polyposis and 12 were unaffected first degree relatives over 35 years of age who had no evidence of colorectal polyposis at endoscopy. Age 35 was used to discriminate between affected and unaffected subjects because in a recent popula- tion based study of subjects under surveillance for familial adenomatous polyposis in $90 \%$ of patients colonic polyposis was found before age 35 years. ${ }^{14}$ The characteristics of the study population are summarised in Table I.

\section{DENTAL PROCEDURES}

Panoramic dental radiographs were coded and evaluated for number, size, and location of jaw lesions by two dentists (JCG and LSL) on separate occasions. There was complete agreement in interpretation. A jaw lesion was defined as a clinically occult radiodensity in the mandible or maxilla, including any well circumscribed area of bone sclerosis or odontoma, 5 as shown in Figure 1. Normal anatomic landmarks such as the genial tubercles in the anterior mandible were not included as occult radio-opaque jaw lesions. The subject was considered positive for this marker if one or more jaw lesions were present.

\section{OPHTHALMOLOGICAL PROCEDURES}

A corrected visual-acuity assessment, a slit lamp examination, and indirect ophthalmoscopy were performed in all subjects by one of two ophthalmologists (EIT and IHM). The examiner was unaware of the clinical diagnosis of the patients. The fundus was evaluated for the presence of pigmented ocular fundus lesions, as shown in Figure 2 and defined previously. ${ }^{6}$ The appearance was recorded using fundus drawings, and photographs were obtained when possible. For the present study a subject was considered positive for the ocular marker if examination of both retinas showed one or more lesions. This criterion is modified from our previous studies in which subjects were considered positive for the pigmented ocular fundus lesions if four or more lesions were noted on fundoscopic examination of both eyes. ${ }^{6}$ Ophthalmoscopy may not detect all ocular lesions in familial adenomatous polyposis patients. In a recent histopathological study by Traboulsi et al of eyes from a necropsy of a patient with familial adenomatous polyposis

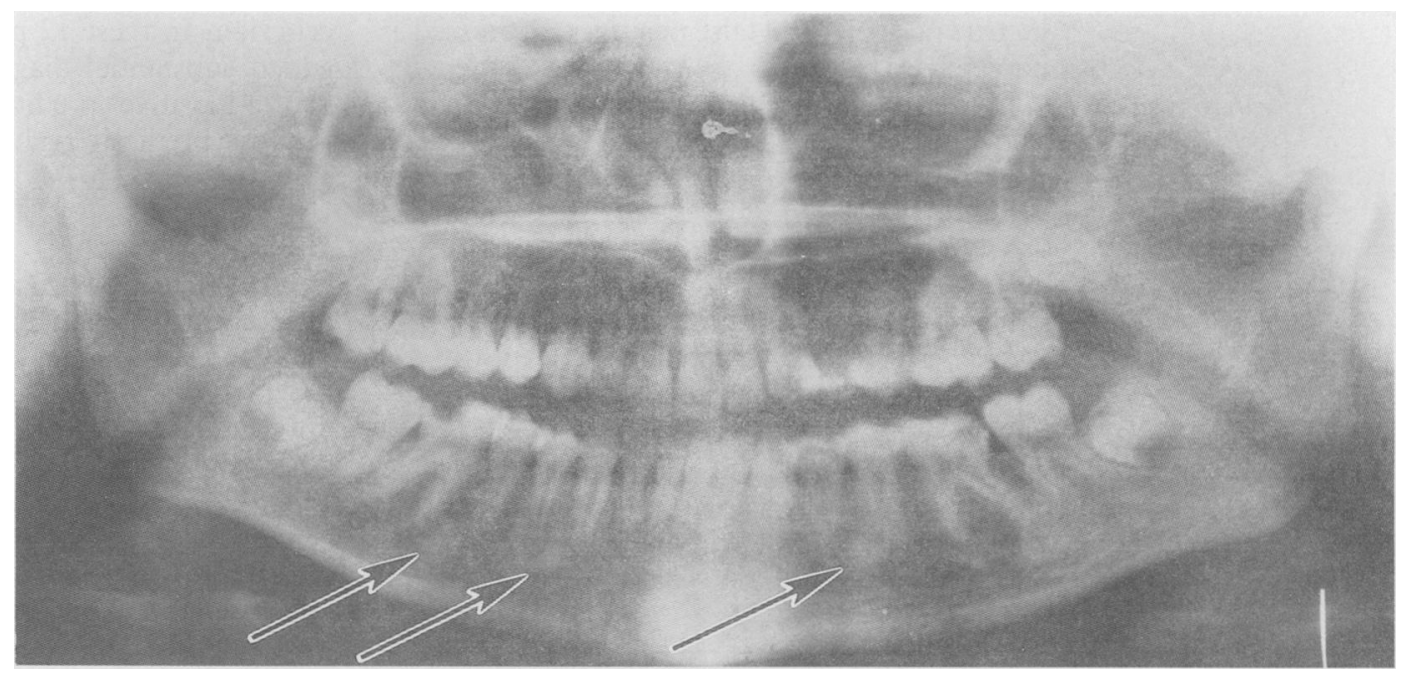

Figure 1: Panorex jaw $\mathrm{x}$ ray in a patient with familial adenomatous polyposis showing multiple occult radio-opaque jaw lesions (arrows). 
TABLE II Frequency of combined phenotypic markers in affected patients and first degree relatives at risk

\begin{tabular}{|c|c|c|}
\hline Subjects & $\begin{array}{l}\text { No }(\%) \text { with } \\
\text { both markers } \\
\text { present }\end{array}$ & $\begin{array}{l}\text { No }(\%) \text { with } \\
\text { both markers } \\
\text { absent }\end{array}$ \\
\hline $\begin{array}{l}\text { Patients with familial adenomatous } \\
\text { polyposis } \\
\text { With extraintestinal manifestations } \\
\text { Without extraintestinal }\end{array}$ & $\begin{array}{l}33(77) \\
31\end{array}$ & $\begin{array}{c}10(23) \\
9\end{array}$ \\
\hline $\begin{array}{l}\text { manifestations } \\
\text { First degree relatives }>35 \text { years of age } \\
\text { With extraintestinal manifestations } \\
\text { Without extraintestinal } \\
\text { manifestations }\end{array}$ & $\begin{array}{l}2 \\
1(8) \\
1^{\star}\end{array}$ & $\begin{array}{c}1 \\
8\end{array}$ \\
\hline
\end{tabular}

^A 41 year old woman with occult radio-opaque jaw lesions, pigmented ocular fundus lesions, skin cysts, and mandibular osteomas but no colorectal polyps.

many more pigmented ocular fundus lesions were present than had been identified by indirect ophthalmoscopy. ${ }^{7}$ Therefore, the change in criterion for positivity was made in an attempt to simplify clinical recognition of these lesions in our study which evaluated the combination of jaw and ocular lesions.

\section{DATA COLLECTION AND ANALYSIS}

A subject was considered to be affected with familial adenomatous polyposis if more than 100 adenomatous polyps were present in the colorectum at surgery or by endoscopic examination. Unaffected subjects were those over 35 years of age with no evidence of polyps on endoscopy. Subjects were labelled positive for the combination of phenotypic markers if they had one or more occult radio-opaque jaw lesions and one or more pigmented ocular fundus lesions.

Sensitivity of the combined and individual phenotypic markers for familial adenomatous polyposis was defined as the percentage of affected patients with a positive test (true positives divided by true positives and false negatives, expressed as percentage). Specificity was defined as the percentage of unaffected subjects with a negative test (true negatives divided by true negatives and false positives, expressed as percentage). Predictive value of a positive test was defined as the percentage of subjects with a positive test who had familial adenomatous polyposis (true positives divided by true positives and false positives, expressed as percentage).

Predictive value of a negative test was defined as the percentage of subjects with a negative test who did not have polyposis (true negatives divided by false negatives and true negatives,

TABLE III Sensitivity, specificity, predictive value of a positive test, predictive value of a negative test, and efficiency for the diagnosis of familial adenomatous polyposis

\begin{tabular}{|c|c|c|c|c|c|}
\hline & \multirow{2}{*}{$\begin{array}{l}\text { Sensitivity } \\
(\%)\end{array}$} & \multirow{2}{*}{$\begin{array}{l}\text { Specificity } \\
(\%)\end{array}$} & \multicolumn{2}{|c|}{ Predictive value (\%) } & \multirow{2}{*}{$\begin{array}{l}\text { Efficiency } \\
(\%)\end{array}$} \\
\hline & & & Positive test & Negative test & \\
\hline \multirow{3}{*}{$\begin{array}{l}\text { Combined } \\
\text { markers } \\
\text { Occult radio-opaque } \\
\text { jaw lesions } \dagger \\
\text { Pigmented ocular } \\
\text { fundus lesions } \ddagger\end{array}$} & 77 & 92 & 97 & 52 & 80 \\
\hline & 84 & 50 & 86 & 46 & 76 \\
\hline & 58 & 100 & 100 & 40 & 67 \\
\hline
\end{tabular}

$\star$ One or more occult radio-opaque jaw lesions and one or more pigmented ocular fundus lesions.

tOne or more alone.

$\ddagger$ Four or more alone. expressed as percentage). Efficiency of the test was defined as the percentage of all subjects correctly classified (true positives and true negatives divided by true positives and false positives and true negatives and false negatives, expressed as percentage).

\section{Results}

Table II summarises the frequency of finding both occult radio-opaque jaw lesions and pigmented ocular fundus lesions in the 55 study subjects. Thirty three of 43 patients with familial adenomatous polyposis were positive for both markers, a sensitivity of $77 \%$. In contrast, only one of 12 first degree relatives of affected subjects who were over 35 years of age and were not affected with familial adenomatous polyposis had both markers (specificity $92 \%$ ). The predictive value of a positive for the combined markers for polyposis was $97 \%$ (33/34), whereas the predictive value of a negative was $52 \%(11 / 21)$. The efficiency of the combined markers was $80 \%$ in this population with a high prevalence of polyposis.

Of 20 kindreds with affected members examined, including two without extraintestinal manifestations, 17 families $(85 \%)$ had at least one affected member with the combined phenotypic markers. Three affected patients from two different kindreds lacking extraintestinal manifestations were evaluated. One member of each family was positive for the combined phenotypic markers. One kindred with extraintestinal manifestations had no jaw or ocular lesions in any of three affected members. If this latter family is excluded from analysis because the phenotypic markers were not informative for this kindred, sensitivity rose to $83 \%$ and predictive value of a negative reached $61 \%$.

Table III compares the diagnostic performance of the combined phenotypic markets with those of one or more occult radio-opaque jaw lesions alone and four or more pigmented ocular fundus lesions alone as used in our previous studies. Strikingly, ocular examination showing four or more lesions has a $100 \%$ specificity and predictive value of a positive. Twelve of 43 affected patients (28\%) had one to three ocular lesions, leading to low sensitivity of this criterion. In these 12 patients the ocular lesions added substantial diagnostic information: they had a positive predictive value of $93 \%$ and negative predictive value of $100 \%$ in this subset.

\section{Discussion}

Investigators have made dramatic progress in locating the genetic abnormality responsible for familial adenomatous polyposis. ${ }^{1+18} \mathrm{~A}$ gene on the long arm of chromosome 5 (5q21-q22) is implicated in the aetiology of this autosomal dominant syndrome. Although the responsible gene has not yet been identified, molecular genetic analysis by polymorphic market probes linked to familial adenomatous polyposis has been used to identify affected family members. ${ }^{19}$ This approach, however, requires linkage analysis including at least two affected subjects within a family. Linkage analysis cannot be done in all 


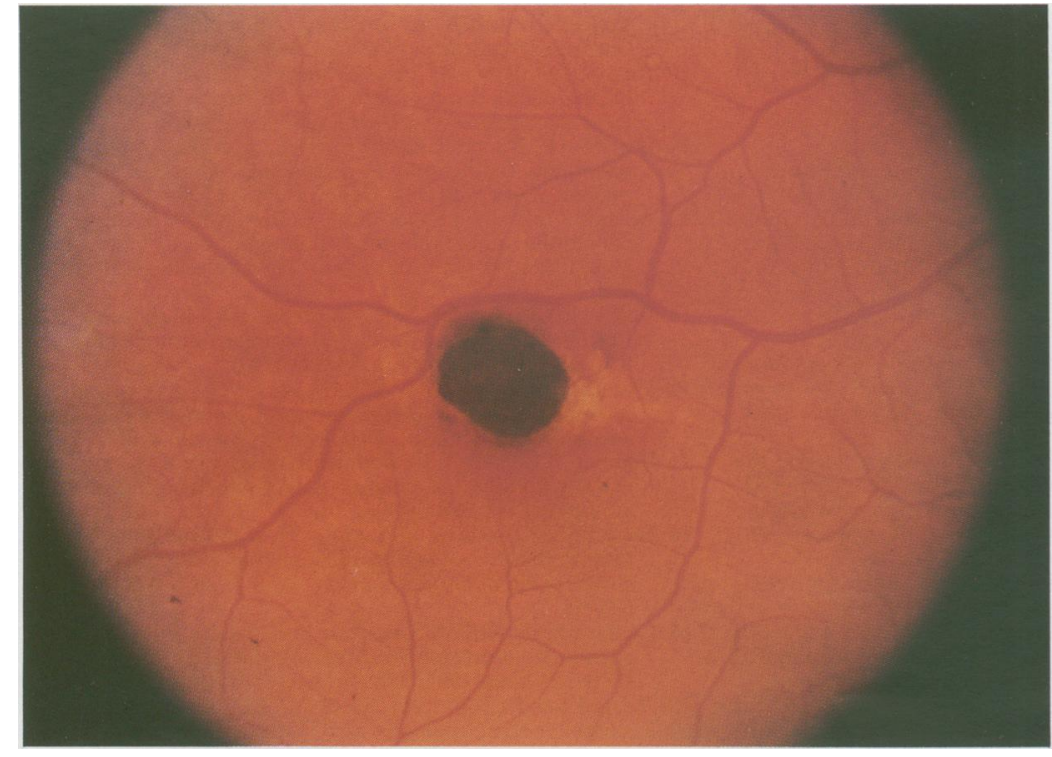

Figure 2: Funduscopic photograph of a patient with familial adenomatous polyposis showing a $1 \mathrm{~mm}$ lesion typical of a pigmented fundus ocular lesion.

families due to lack of polymorphisms for probes. In addition, approximately one third of polyposis cases represent spontaneous mutations without affected parents or siblings.

Our study focused on the phenotypic alterations seen in familial adenomatous polyposis. The presence of phenotypic markers implies that the genetic abnormality is being expressed. The importance of the disparities between phenotypic and genotypic markers is emphasised by two lines of evidence. Firstly, adenomatous polyposis with extraintestinal manifestations (Gardner syndrome) and without extraintestinal manifestations (familial polyposis) are both linked to the same chromosome 5q21-22 locus. Secondly, a recent report noted a wide variety of phenotypic expression in one family in patients inheriting genetic markers for familial adenomatous polyposis,$^{20}$ including even striking variation in the numbers of colorectal adenomas, which are the hallmark of this disease. The combined phenotypic markers currently have an advantage over genetic analysis because the markers are simple to evaluate, readily available, and require the cooperation of only the patient under investigation.

Several authors have now reported the value of occult radio-opaque jaw lesions or pigmented ocular fundus lesions as phenotypic markers in familial adenomatous polyposis. ${ }^{321}$ These clinical markers enable the physician to tailor endoscopic screening programmes and predict the development of disease. Patients who inherit polyposis typically have colorectal polyposis in adolescence or early adulthood, and affected young children who later develop colorectal polyposis are initially free of polyps. Although prophylactic colectomy is the current treatment, identification of affected subjects before polyps appear may assume increasing importance if chemopreventive medical regimens become available. For example, the non-steroidal antiinflammatory drug sulindac has been reported anecdotally to reduce the number of or even eliminate colorectal polyps in familial adenoma- tous polyposis patients. ${ }^{22}$ These and other drugs have potential for use as chemopreventive agents. Moreover, clinical recognition of these phenotypic markers raises the suspicion of polyposis in patients without a positive family history who are new genetic mutations for this disorder. Also, knowledge that the patient has polyposis contributes to the appropriate management of offspring. A major advantage of the ocular and jaw lesions is that both are detectable in early life by non-invasive methods and they occur in a high percentage of subjects who are affected by familial adenomatous polyposis.

One disadvantage of these lesions as markers of familial adenomatous polyposis is that they can be seen occasionally in normal subjects. For example, Traboulsi et $a l^{6}$ found that two of 42 control subjects had bilateral pigmented ocular fundus lesions and one third of control subjects had at least one lesion. On the other hand, we expected the simultaneous occurrence of both markers in an unaffected subject to be unusual. The predictive value of positive combined phenotypic markers when both ocular and jaw lesions were present was $97 \%$.

Interestingly, the one patient at risk who had positive combined markers without colorectal polyposis at age 41 also had other extraintestinal features of familial adenomatous polyposis including skin cysts and osteomas at the angle of the jaw. We intend to follow this patient up and it will be interesting to see if she ultimately develops colorectal polyposis.

Our study showed that the absence of both markers does not indicate that familial adenomatous polyposis will not be inherited. In 17 of 20 families with affected members examined for both markers at least one affected subject was positive for both markers. In one family, however, with extraintestinal manifestations we examined three affected patients, none of whom was positive for either ocular or jaw lesions. Thus there is heterogeneity of these extraintestinal lesions in familial adenomatous polyposis, as has been described previously.

From the results of our studies, we recommend the following stepwise application of single and combined phenotypic markers to identify patients with familial adenomatous polyposis in the absence of colorectal polyposis: indirect ophthalmoscopic examinations should be done first. Patients with four or more pigmented ocular fundus lesions should be considered to have inherited the disorder and require no additional marker studies. Patients with one to three such lesions should have jaw radiographic examinations, and those positive for occult radio-opaque jaw lesions can be considered to be affected with familial adenomatous polyposis. The absence of ocular lesions, however, cannot be used to rule out the disease.

Our study of a large number of kindreds with familial adenomatous polyposis has confirmed that the combination of occult radio-opaque jaw lesions and pigmented ocular fundus lesions is reliable for identifying affected patients. The presence of both markers in a patient at risk indicates high probability of inheritance of and expression of the genetic abnormality in familial adenomatous polyposis. Nevertheless, the 
decision to do a colectomy in such patients should depend on the demonstration of colorectal adenomatous polyposis.

Supported by the Clayton Fund, the McAshan Fund, the Laura $\mathrm{C}$ Krieble Fund, and by NIH grant RO1-CA44555. GJO is recipient of a gastrointestinal pathology fellowship at The Johns Hopkins Medical Institutions from the Netherlands Organisation for Scientific Research (NWO) and from the Netherlands Digestive Disease Foundation.

1 Bussey HJR. Familial polyposis coli. Family studies, histopathology, differential diagnosis, and results of treatment. Baltim.

2 Boland CR, Itzkowitz SH, Kim YS. Colonic polyps and the gastrointestinal polyposis syndromes. In: Sleisenger $\mathrm{MH}$ Fordtran JS, eds. Gastrointestinal disesase: pathophysiology, diagnosis, and management. 4th ed. Philadelphia: WB Saunders, 1989: 1500-7.

3 Haggitt RC, Reid BJ. Hereditary gastrointestinal polyposis syndromes. Am F Surg Pathol 1986; 10: 871-87.

4 Utsunomyia J Nakamura T. Osteomatous changes and tooth abnormalities found in the jaws of patients with familial abnormalities found in the jaws of patier

5 Offerhaus GJA, Levin LS, Giardiello FM, Krush AJ, Welsh $\mathrm{SB}$, Booker SV, et al. Occult radiopaque jaw lesions in $\mathrm{SB}$, Booker SV, et al. Occult radiopaque jaw lesions in familial adenomatous polyposis coli and hereditary nonpo

6 Traboulsi EI, Krush AJ, Gardner EJ, Booker SV, Offerhau GJA, Yardley J, et al. Prevalence and importance of pigmented occular fundus lesions in Gardner's syndrome. NEnglf Med 1987; 316: 661-7.

7 Traboulsi EI, Murphy S, Dela Cruz ZC, Maumenee IH, Green WR. A clinicopathological study of the eyes in familial adenomatous polyposis with extracolonic manifestations adenomatous polyposis with extracolonic manifestations

8 Blair NP, Trempe Cl. Hypertrophy of the retinal pigment epithelium associated with Gardner's syndrome. Am $\mathcal{f}$ Opithelium associated with

9 Traboulsi EI, Maumenee IH, Krush AJ, Alcorn D, Giardiello FM, Burt RW, et al. Congenital hypertrophy of the retinal pigment epithelium predicts colorectal polyposis in Gardner's Syndrome Arch Ophthalmol 1990; 108: 525-6.

10 Austin BW, Monie AJ. A comparative study of the prevalence of mandibular osteosclerosis in patients of Asiatic and Caucasian origin. Aust Dent $\mathcal{F} 1984 ; 29$ : $36-43$

11 Barrett AP, Waters BE, Griffiths CJ. A critical evaluation of panoramic radiography as a screening procedure in denta practice. Oral Surg Oral Med Oral Pathol 1984; 57: 673-7.

12 Allatar MM, Baughman RA, Collett WK. A survey of panoramic radiographs for evaluation of normal and pathologic findings. Oral Surg Oral Med Oral Pathol 1980; 50 $472-8$.

13 Lewis RA, Crowder WE, Eierman LA, Nussbaum RI Ferrell RE. The Gardner syndrome: significance of ocular features. Ophthalmology 1984; 91:916-25.

14 Vasen HFA, Griffioen G, Offerhaus GJA, et al. The value of screening and central registration of families with familia adenomatous polvposis. Dis Colon Rectum 1990; 33: 227-33.

15 Bodmer WF, Baily CF, Bodmer J, et al. Localization of the gene for familial adenomatous polyposis coli on chromosome 5. Nature 1987; 328: 614-6.

16 Nakamura Y, Lathrop M, Leppert M, et al. Localization of the genetic defect in familial adenomatous polyposis within small region of chromosome 5. Am f Hum Genet 1988; 43 . 638-44.

17 Leppert M, Dobbs M, Scrambler P, et al. The gene for familia adenomatous polyposis coli maps to the long arm of chromosome 5. Science 1987; 238: 1411-3.

18 Meera Khan P, Tops CMJ, Broek MVD, et al. Close linkage of a highly polymorphic marker (D5S37) to familial adenomaa highly polymorphic marker (D5S37) to familial adenomatous polyposis (FAP) and confirmation of FAP localiz

19 Tops CMJ, Wijen JT, Griffioen G, et al. Presymptomatic diagnosis of familial adenomatous polyposis by bridging DNA markers. Lancet 1989; ii: 1361-3.

20 Leppert M, Burt T, Hughes JP, Samowitz W, Nakamura Y, Woodward S, et al. Genetic analysis of an inherited predisposition to colon cancer in a family with a variable number of adenomatous polyps. $N$ Engl f Med 1990; 322: 90+-8.

21 Romania A, Zakov N, McGannon E, Schroeder T, Heven F, Jagelman DG. Congenital hypertrophy of the retinal pigmentation epithelium in familial adenomatous polyposis. Ophthalmology 1989; 96: 879-84.

22 Waddell WR, Ganser GF, Cerise EJ, Loughry RW. Sulinda for polyposis of the colon. Am $\mathcal{F}$ Surg 1989; 157: 175-9. 